\title{
Takayasu arteritis combined with congenital supravalvular aortic stenosis
}

Yijie $\mathrm{Hu}, \mathrm{MD}, \mathrm{PhD}$, and Qianjin Zhong, MD, PhD

A 14-year-old girl was admitted for syncope, with malaise, fever, and night sweats. When she was 3 years old, congenital supravalvular aortic stenosis had been diagnosed with

\footnotetext{
From the Department of Cardiovascular Surgery, Institute of Surgery Research, Daping Hospital, Third Military Medical University, Chongqing, People's Republic of China.

Disclosures: Authors have nothing to disclose with regard to commercial support. Received for publication June 7, 2013; accepted for publication June 12, 2013; available ahead of print July 24, 2013.

Address for reprints: Qianjin Zhong, MD, PhD, No. 10 Changjiang Zhi Rd, Yuzhong

District, Chongqing, People's Republic of China (E-mail: zhongqianjin@qq.com).

J Thorac Cardiovasc Surg 2013;146:1545-6

$0022-5223 / \$ 36.00$

Copyright (C) 2013 by The American Association for Thoracic Surgery

http://dx.doi.org/10.1016/j.jtcvs.2013.06.012
}

echocardiography; however, she received no interventions at that time. Physical examination revealed a parasternal systolic murmur at the first intercostal space and bilateral absent radial pulse. Blood tests indicated severe anemia $(59 \mathrm{~g} / \mathrm{L})$ and elevated erythrocyte sedimentation rate $(>140 \mathrm{~mm} / \mathrm{h})$, leukocyte count $\left(19.44 \times 10^{9} \mathrm{cells} / \mathrm{L}\right)$, and C-reactive protein $(168.12 \mathrm{mg} / \mathrm{L})$. Severe vascular lesions were seen on computed tomography and magnetic resonance imaging, including a cluster of aneurysms of the ascending aorta and arch (Figure 1, asterisks), occlusion of brachiocephalic trunk artery, and dilation of the left coronary artery (Figure 1, A, short arrow), as well as

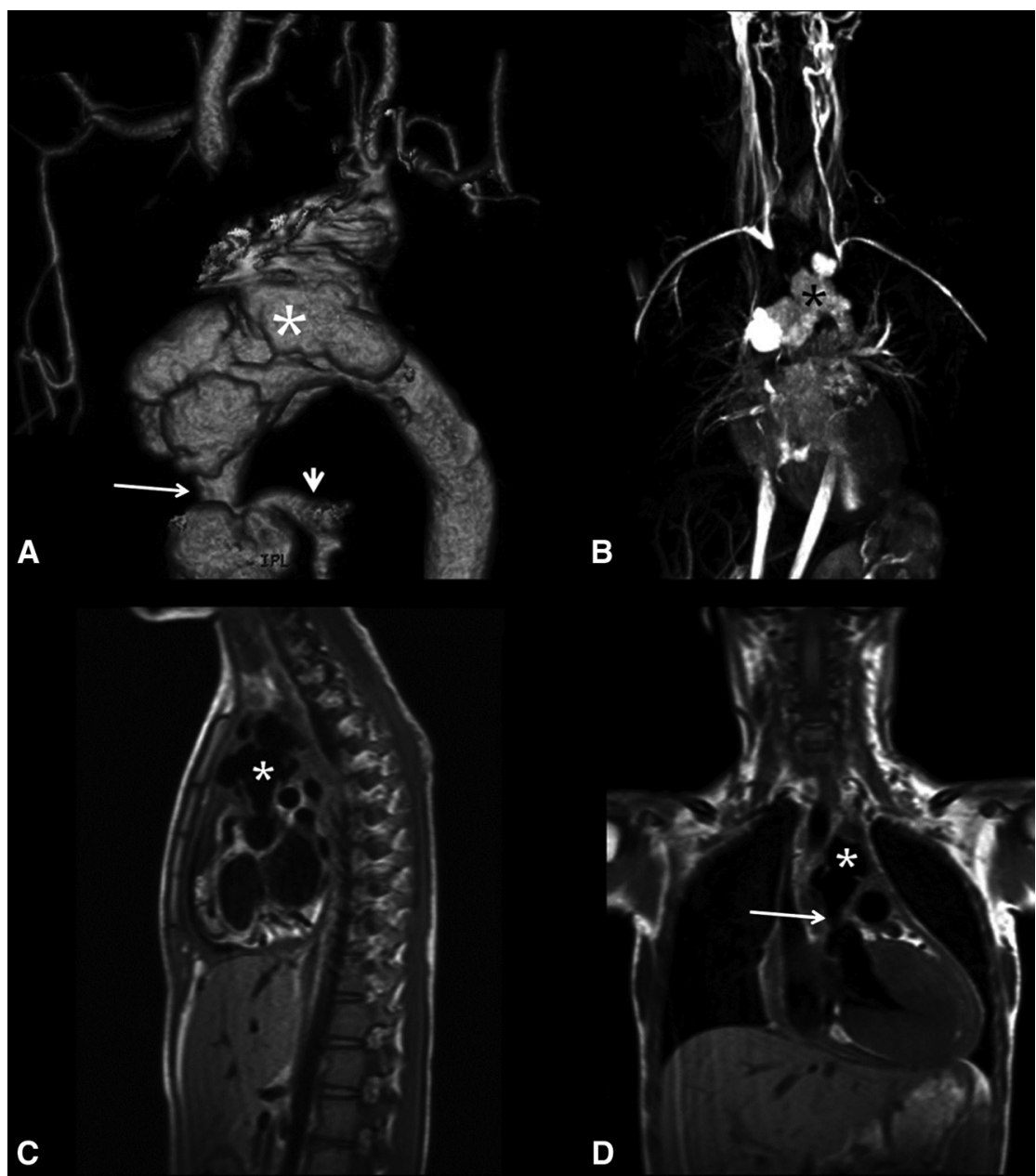

FIGURE 1. Imaging features of Takayasu arteritis combined with congenital supravalvular aortic stenosis. Severe vascular lesions and obviously concentric left ventricular hypertrophy are shown. A, Three-dimensional computed tomographic scan. B, Magnetic resonance angiography. C, Sagittal plane in magnetic resonance imaging. D, Coronal plane in magnetic resonance imaging. Asterisk, Aneurysms of the ascending aorta and arch. Short arrow, Dilation of the left coronary artery. Long arrow, Supravalvular aortic stenosis. 
supravalvular aortic stenosis (Figure $1, A$ and $D$, long arrow) and obvious concentric left ventricular hypertrophy.

Takayasu arteritis, combined with congenital supravalvular aortic stenosis, was diagnosed according to the American College of Rheumatology criteria. This combination and the extent of the aortic lesions are extremely rare. The typical features of Takayasu arteritis are thickening of aortic wall and stenosis or dilation of aorta and its branches. Higher velocity and eccentric flow jets in the patient with supravalvular aortic stenosis may also lead to increased shear stress on the ascending aortic wall of Takayasu arteritis, however, and thus vagarious imaging is characteristic. The combination of conditions complicated repair of the supravalvular aortic stenosis and reconstruction of the aortic arch and its branches. High-dose corticosteroids were applied to ameliorate acute exacerbations and antiplatelet therapy was administered before further surgical intervention. 